\title{
Hydrogel Intraocular Lens Experience With Endocapsular Implantation
}

\author{
W. J. RICH, ${ }^{1}$ P. I. CONDON,$^{2}$ S. P. B. PERCIVAL ${ }^{3}$ \\ Exeter, Waterford, Scarborough.
}

\begin{abstract}
Summary
The experience is presented of three independent surgeons using Hydrogel posterior chamber intraocular lenses in a combined series of 157 endocapsular cataract extractions. One hundred and fifty of these eyes were examined after a minimum follow-up period of one year and $92.0 \%$ achieved visual acuity of $6 / 12$ or better, and $98.6 \%$ achieved this if pre-existing pathology was excluded. Insertion of this lens has proved to be simple, the adaptions of technique required are described and the complications are presented and analysed.
\end{abstract}

Harold Ridley ${ }^{1}$, the inventor and pioneer of the intraocular lens implant, made a fortunate choice of material in polymethylmethacrylate (PMMA), a lens implant material which has withstood the test of time and has been demonstrated not only to be inert in the eye but to have good optical properties ${ }^{2}$. Advances in other medical fields and in contact lens technology have shown that other biologically acceptable materials are available which may offer additional useful properties for an intraocular lens implant ${ }^{3.6}$. A flexible implant which might be folded to allow insertion through the small incision required for phakoemulsification would offer a reduction in post-operative astigmatism and promote early rehabilitation. The hydrogel poly 2/hydroxyethylmethacrylate ( $\mathrm{P}$ HAEMA) has been shown to be inert and to be biocompatible with ocular tissues ${ }^{7.11}$ and also to be less damaging to cornea and iris than PMMA. Hydrogel lenses can be sterilised by autoclave and have elastic and surface properties which render loops or dialling holes unnecessary. The authors antici- pated that a flexible lens would give problems with decentration or flexing if situated partially within the capsular bag. The endocapsular technique of insertion ${ }^{12}$ was chosen because it was a technique with which they already had experience and which offered a certain method of achieving total placement of the intraocular lens within the capsular bag.

\section{Materials and Methods}

One hundred and fifty seven eyes with non-complicated senile cataract (age range 57-92 years, mean 76,80 females, 57 males) were operated on by the three authors. Each surgeon operated upon his own consecutive series of patients and results and experiences have been pooled. All three surgeons used the same endocapsular technique. A linear horizontal capsulotomy was fashioned using a bent 27 gauge needle at the junction between the upper third and lower two thirds of the anterior capsule. The nucleus was then mobilised by hydrodissection using a Rycroft cannula to inject a small volume of balanced

\footnotetext{
Correspondence to W. J. Rich, West of England Eye Infirmary Magdalen, Street, Exeter.

1 From the West of England Eye Infirmary, Exeter;

2 Waterford Regional Hospital, Waterford, Eire;

3 Scarborough District Hospital, Yorkshire.
} 
salt solution underneath the capsule. The nucleus was rotated and expressed and two sutures tied to give partial wound closure while the irrigation/aspiration was carried out using non automated techniques. The hydrogel lens, held by special curved forceps at the junction between the haptic and the optical zone, was inserted through the wound edge and then advanced underneath the anterior capsule edge into the capsular bag as far as it would slide; at this stage, the upper haptic of the lens would be resting anterior to the iris. A blunt dialling hook or sandblasted capsule polisher was then used to rotate the lens and move it inferiorly so that the upper haptic could slide underneath the upper anterior capsule; the lens was left with its long axis close to vertical. One author (PIC) used an irrigating cannula to rotate the lens into the 3-9 o'clock position. Certainty of placement of the lens within the capsular bag was confirmed by noting the anterior capsular flap in front of both lens haptics. Anterior capsulotomy was then performed by making one or two vertical incisions using special long-bladed anterior capsule scissors at the right or left hand margin of the pupil and completed using McPherson's forceps to tear away the flap between the incisions. The wound was closed with interrupted 10.0 nylon sutures, no iridectomy was performed and at the end of surgery a sub-conjunctival injection of $2.5 \mathrm{mg}$ Betamethasone and $20 \mathrm{mg}$ Gentamicin solution was given.

Post-operatively patients were given topical steroid and antibiotic drops, initially four times per day, and reduced gradually over the subsequent weeks. Patients were examined by the surgeon personally on the first and second postoperative day and on at least four occasions subsequently. At six months and at one year slit lamp examination was carried out with the pupil fully dilated to determine the position of the lens optic in relation to the central $5 \mathrm{~mm}$ pupillary zone. The Goldman 3-mirror lens was used to ascertain the relation of the lens haptics to the capsular flaps and to inspect for the presence of iris bulge anterior to the haptic tips.

\section{Complications and Results}

One hundred and fifty one of the 157 operated eyes were available for examination one year after implant surgery. Six patients had died during the year. The Hydrogel lens was removed from one eye because of decentration and this has been excluded from the one year results.

\section{Operative Complications.}

Localised rupture of the posterior capsule occurred in five eyes and partial rupture of the zonule occurred in one eye, these defects were felt to be small enough to allow safe insertion and support for the intraocular lens. In two eyes a sphincter tear occurred at the time of nucleus expression caused by poor pupillary dilatation. One eye had a dense axial plaque on the posterior capsule and primary posterior capsulotomy was performed.

\section{Postoperative Complications (Table I).}

Iris prolapse caused by trauma occurred in one eye on the first postoperative day and surgery was required to reposition the iris. Two eyes had a shallow anterior chamber on the first postoperative day caused by wound leakage, in neither case was surgical intervention required. In one of these eyes the lens was noted to be flexed into an $\mathrm{S}$ configuration. By day two when the anterior chamber had completely reformed, the lens had resumed its normal contour but both haptics were noted to have come out of the capsular bag and to rest in the ciliary sulcus. In the second case the lens did not flex but the pupil has remained permanently peaked. Both eyes had visual acuity of $6 / 6$ one year after surgery.

Fibrinoid uveitus occurred in ten eyes between the fourth and eight post-operative day and presented as a fibrinous exudate in the anterior chamber with adhesions to the lens, iris and anterior capsule without hypopyon. Topical steroids and mydriactics were given

\section{Table I Post-operative Complications}

Fibrinoid uveitis

Wound leak

Lens flexing with shallow anterior chamber

Iris prolapse

Lens haptic subluxation 
and in all cases resolution occurred within two weeks, and in later examinations, the only residual evidence of the uvietus were posterior synechiae to the anterior capsule from the iris. There were no cases of postoperative infection, hyphaema, corneal decompensation, persistant raised intraocular pressure or retinal detatchment.

\section{Secondary Interventions (Table II).}

The implant was removed from one eye because of decentration caused by partial capsular rupture. The edge of the optic was visible in the undilated pupil and caused distorted vision and halo formation. Six weeks after implantation the Hydrogel lens was removed without difficulty and replaced with an interior chamber implant to regain $6 / 6$ visual acuity. Subluxation of one haptic from the capsular bag with accompanying decentration of the intraocular lens occurred on the second post-operative day in one eye, the lens was repositioned into the capsular bag using sodium hyaluronate and a Sinskey hook. Multiple interventions were required in an eye in which there had been ballooning of the iris during irrigation. Severe postoperative iritis caused synechiae from the iris to the anterior capsule, a distorted and updrawn pupil and posterior capsular opacification. Surgical division of the synechiae was followed by Argon laser pupilloplasty and YAG laser posterior capsulotomy. Vision one year postoperatively was $6 / 60$ with cystoid macular oedema present. Posterior capsulotomy was deemed neccessary in three eyes and was performed by YAG laser without difficulty and with restoration of previous acuity.

\section{Examination at One Year. \\ Visual Acuity}

The visual acuity results one year after surgery are shown in Table III. One hundred and thirty eight of the 150 patients $(92.0 \%)$ achieved corrected visual acuity of $6 / 12$ or better. If eyes with ocular diseases unrelated to cataract surgery such as senile macular disease, vascular occlusions and diabetic retinopathy are excluded, 138 of 140 eyes $(98.6 \%)$ achieved visual acuity of $6 / 12$ or better and 130 of 132 eyes (98.6\%) achieved cor- rected acuity of $6 / 9$ or better. Table IV shows the conditions responsible for visual acuity of 6-12 or less. Two eyes had visual acuity of 6/ 18 six months postoperatively but, with resolution of cystoid macular oedema, had improved to $6 / 9$ at the one year examination.

Decentration and Position of the Lens Haptics.

Decentration was judged to be significant, with the edge of the optic visible in the undilated pupil in three eyes. In one of these eyes

Table II Secondary Procedures

Iris prolapse repair

Removal of I.O.L.

Repositioning of I.O.L.

Argon laser pupilloplasty

Yag laser posterior capsulotomy

Table III Visual Acuity at 12 months.

\begin{tabular}{cc}
\hline Visual Acuity & Total \\
$6 / 6$ & 96 \\
$6 / 9$ & 34 \\
$6 / 12$ & 8 \\
$6 / 18$ & 5 \\
$6 / 24$ & 1 \\
$6 / 60$ & 3 \\
$6 / 60$ & 3 \\
\hline Total & 150 \\
\hline
\end{tabular}

Table IV Conditions responsible for visual acuity less than $6 / 9$ at twelve months.

\begin{tabular}{lcccccc}
\hline Visual acuity & $6 / 12$ & $6 / 18$ & $6 / 24$ & $6 / 60$ & \multicolumn{3}{c}{$6 / 60$ Total } \\
Senile Macular & 7 & 2 & 1 & 2 & 2 & 14 \\
$\begin{array}{l}\text { Degeneration } \\
\text { Cystoid Macular }\end{array}$ & & & & & & \\
$\begin{array}{l}\text { Oedema } \\
\text { Central Retinal }\end{array}$ & & & & & & 1 \\
$\begin{array}{l}\text { Artery Occlusion } \\
\text { Branch Retinal } \\
\text { Vein Occlusion }\end{array}$ & 1 & 1 & & & & 2 \\
$\begin{array}{l}\text { Posterior Capsule } \\
\text { Fibrosis }\end{array}$ & & 1 & & & & 1 \\
$\begin{array}{l}\text { Diabetic } \\
\text { Retinopathy }\end{array}$ & & 1 & & & & 1 \\
\hline \begin{tabular}{l} 
Total \\
\hline
\end{tabular} & 8 & 5 & 1 & 3 & 3 & 20 \\
\hline
\end{tabular}


symptoms necessitated removal of the lens and it is therefore excluded from the results at one year. The other two eyes were asymptomatic, did not require treatment and had visual acuity of $6 / 6$ at one year. These three eyes, with significant decentration, were all in the group of five eyes with partial zonular or capsular rupture.

Minor decentration such that the edge of the optic was visible within the pupil dilated to $5 \mathrm{~mm}$, was present in twenty-four eyes. Only one of these patients had symptoms (glare when driving at night) and in none did the degree of decentration progress over the one year period. Decentration occurred predominently in an upwards direction (twentythree eyes) and in a horizontal direction in only one eye. Table $\mathrm{V}$ shows the relationship of these minor decentrations to lens orientation and haptic position. One hundred and twenty eyes were found to have both lens haptics still situated where they had been placed at surgery, within the capsular bag. In 15 eyes, one haptic was still behind the anterior capsule and in 10 of these, decentration was noted. In 3 eyes, both lens haptics were in front of the anterior capsular flaps and in 7 eyes it was not possible to see the position of the anterior capsular flaps although a gap between the iris and the

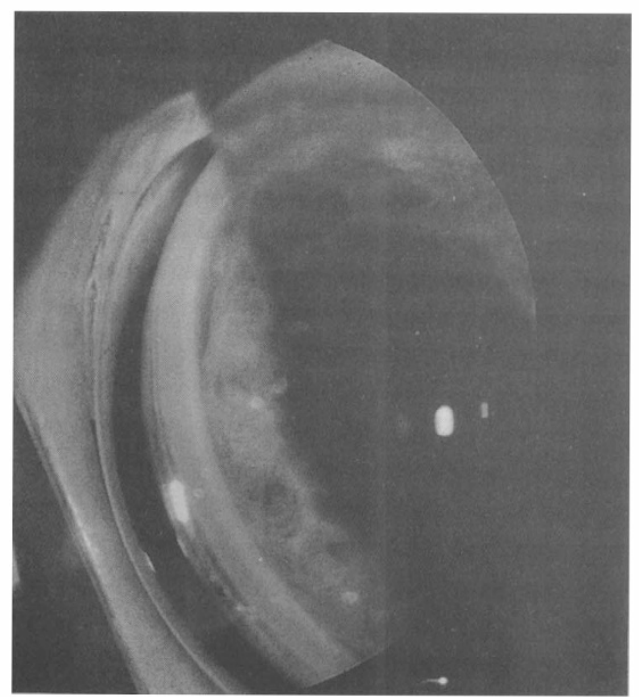

Fig. 1 Bulging of the iris into the angle shown by gonioscopy. intraocular lens suggested endocapsular position. Iris bulge into the anterior chamber angle (Fig. 1) was observed in six eyes with decentered and asymmetrically positioned lenses. The haptic in the area of the iris bulge was found to be in front of the ciliary sulcus and the other haptic was in the capsular bag. In three of these eyes the lens haptics were observed to be flexed. In none of these eyes was depigmentation of the iris, peripheral anterior synechiae or raised intraocular pressure observed.

\section{Pupillary Abnormalities.}

The pupil was irregular in 33 eyes. In 26 of these there were posterior synechiae between the iris and the anterior capsular flap. In one eye the pupil was peaked due to traumatic shallowing of the anterior chamber postoperatively. In two eyes there were synechiae between the intraocular lens implant and the iris. In six eyes the pupil was mildly atonic when compared to the other eye

\section{Discussion.}

The visual acuity results bear favourable comparison with other published series of cataract extractions with intraocular lens implantation at a similar follow up period ${ }^{13-}$ 18. Complications have been few and several points deserve discussion. Persistant cystoid macular oedema accounted for vision less than $6 / 12$ in only one eye at one year $(0.7 \%)$ and this was in an eye in which multiple interventions had been required, vision at one year was $6 / 60$.

The fibrinoid anterior uveitus which occurred in 10 eyes followed a benign course, all cases responded rapidly to simple local treatment and had good visual outcome. This incidence may seem somewhat high and may be related to the endocapsular technique rather than the hydrogel lens. Fibrinoid anterior uveitis was present on the sixth postoperative day in both eyes of one patient who had received a hydrogel implant in one eye and, one day later, a PMMA implant in the other eye. Both eyes followed a similar course and settled satisfactorily with topical treatment.

Flexibility of the Hydrogel lens and the effect of this upon lens position and deformation is of interest. There is no doubt that it is 
possible for the haptics to flex either within or outside the capsular bag, indeed, the lens is designed with a convex posterior surface and slight anterior flexure of the haptics. Flexing of the lens haptic may cause a forward bulging of the iris into the angle of the anterior chamber angle but the degree has remained static during the period of observation and, in contrast with the experience reported with looped lenses ${ }^{19}$, there were no overlying iris transillumination defects, microhyphaemata or secondary glaucoma.

The Hydrogel lens has a diameter of $12 \mathrm{~mm}$. and when placed with both haptics within the capsular bag the diameter of which is slightly smaller at $10.32 \mathrm{~mm} .{ }^{20}$ it tends to stretch the posterior capsule tightly against its posterior surface and also to accentuate the posterior flexure. An asymmetrical position of the lens, with one haptic in the capsular bag and other external to it, is likely to cause unbalanced forces within the capsular bag resulting in decentration of the lens in a manner similar to decentration experienced with looped PMMA posterior chamber lenses. Ninety two per cent of such asymmetrically placed looped lenses have been reported to have significant decentration ${ }^{21}$. While only three implants were judged to be decentred to a clinically significant degree (the optic edge visible in the undilated pupil), twenty four were decentred slightly. It is interesting that one of the authors, (P.I.C.) routinely orientated the lens with its long axis horizontally and that 7 out of the 8 of his lenses which decentred had both haptics in the capsular bag. It is suggested that with horizontal placement, upward decentration was primarily due to anterior capsular flap asymmetry where the larger inferior flap adheres to the posterior capsule so squeezing the optic of the implant upwards when unopposed by a symmetrical force of contraction from above. Vertical orientation of the lens haptics, employed by the other two authors, seems to be associted with decentration if one of the haptics is not within the capsular bag and it again occurs in an upward direction because the larger inferior capsular recess retains the lens more securely. The overall decentration rate was $18 \%$ and only three cases were clinically significant. It is interesting to compare this with the postmortem study of eyes with posterior chamber lenses by Apple et al. ${ }^{22}$ which reported $71 \%$ incidence of optical irregularities defined as optic edges, positioning holes or loop-optic junctions seen in or within $0.5 \mathrm{~mm}$. of the pupillary aperture. Thus the authors' original fear that a flexible implant might give rise to problems with flexure and decentration has not been borne out in practice.

Posterior capsule opacification appears to be developing infrequently in this series, at least in the first year, with only three patients having required YAG laser capsulotomy. Posterior capsulotomy rates with PMMA lenses between $3.6 \%$ and $9.0 \%{ }^{24}, 25$ have been reported in the first year after surgery. Silicone posterior chamber lens implants have been reported in one series to be associated with $27 \%$ capsulotomy rate after one year. The authors believe that the natural posterior flexure of this lens stretches and applies the posterior capsule to its posterior surface and that this may retard cellular proliferation. The hydrogel material appears to remain free from deposits or synechiae and it is interesting that in only two eyes was an adhesion observed between the iris and the lens.

The surgical technique which the three authors used for insertion of the intraocular lens proved reliable and easy. For insertion it was found convenient to hold the lens with curved forceps at the junction between the optic and the haptic, a technique which gives surprising rigidity to the lens. The shape and surface characteristics of the lens enable it to glide naturally into the capsular bag inferiorly without the routine use of sodium hyaluronate, and by the manoeuvres already described, rotation of the upper haptic behind the superior capsular flap presented little problem. When an instrument such as a collarstud iris retractor or dialling hook rests on the hydrogel lens surface characteristics are such that good adhesion is present and movement of the lens can be achieved without the need for dialling holes. It was the feeling of the authors that the implantation of this particular lens was more easily accomplished than that of any other posterior chamber lens in their experience. While 
longer follow up is awaited with interest the stability of the lens and the results thus far seem to auger well for the future of hydrogel intraocular lenses.

The authors wish to thank Mrs P. Cochram for secretarial help and Miss K. Jones for photographic assistance.

The Hydrogel lens used in this study was manufactured by Alcon Laboratories Inc.

\section{References}

${ }^{1}$ Ridley $\mathrm{H}$. Intraocular acrylic lenses: a recent development in the surgery of cataract. $\mathrm{BrJ}$ Ophthalmol 1952; 36: 113-22.

2 Drews RC. Lens implantation: lessons from the first million. Trans Ophthalmol Soc UK 1982; 102: 505-9.

${ }^{3}$ Wichterle O, Lim D. Hydrophilic gels for biological use. Nature 1960; 185: 117-8.

${ }^{4}$ Wichterle O. Hydrogels. In: Mark HF, Gaylord NG, Bikales N, eds, Encyclopedia of Polymer Science and Technology, New York, Interscience, 1971, 273-290.

${ }^{5}$ Wichterle $\mathrm{O}$. The beginning of the soft lens. In:Ruben M, ed, Soft Contact Lenses: Clinical and applied Technology, New York, John Wiley and Sons, 1978, 3-5.

${ }^{6}$ Simpson BJ. Hyrdon: A hydrophilic polymer. Biomed Eng 1969; 4: 65-8.

${ }^{7}$ Chambers DW, Dillingham EO, Autian J, Toxicity testing of poly 2-hydroxyethyl methacrylate contact lens. Invest Ophthalmol 1974; 13: (Supp) 43-467.

${ }^{8}$ Mehta KR, Sathe SM, Karyekar SD. The soft intraocular implant. In Trevor-Roper P.D.ed. 6th Congress of European Society of Ophthalmology. London, Royal Society of Medicine, 1981; 859-63.

${ }^{9}$ Barrett GD, and Constable IJ. Corneal endothelial loss with new intraocular lenses. Am J Ophthalmol 1984; 98: 157-63.

${ }^{10}$ Mehta KR, Sathe SW, Karyekar SD. The new soft intraocular lens implant. Am Intraocular Implant Society J. 1978; 4: 200-4.

${ }^{11}$ Barrett GD, Constable IJ, Stewart AD. Clinical results of hydrogel lens implantation. $J$ Cat Refract Surg 1986; 12: 623-31.

12 Galand A, Van Oye R, Budo C, et al. Results of implantation in the capsular bag; a short term review of 1,588 cases. Trans Ophthalmol Soc UK 1985; 104: 563-6.

13 Jaffe NS, Eichenbaum DM, Clayman HM, Light DS. A comparison of 500 Binkhorst implants with 500 routine intracapsular cataract extractions. Am J Ophthalmol 1978; 85: 24-7.

${ }^{14}$ Southwick PL, Olson RJ. Shearing posterior chamber intraocular lens: five years postoperative results. Am Intraocular Implant Soc J. 1984; 10: 318-23.

${ }^{15}$ Pearce JL. Current state of posterior chamber intraocular lenses after intracapsular and extracapsular cataract surgery. Trans Ophthalmol Soc UK 1981; 101: 73-76.

${ }^{16}$ Absolon MJ. Experience with Choyce anterior chamber implant in the correction of aphakia. Trans Ophthalmol Soc UK 1981; 101: 69-72.

${ }_{17}$ Cheng. H. I. Cataract Surgery : interim results. Br J Ophthalmol 1986; 70: 402-10.

18 Van Oye R, Budo C, Galand A, et al. two year postoperative results of Galand lens implantation. Am J Cat Refract Surg 1986; 12: 135-9.

${ }^{19}$ Johnson SH, Kratz RP, Olson PF. Iris transillumination defect and microhyphaema syndrome. Am Intraocular Implant Soc J 1984; 10: $425-8$.

${ }^{20}$ Galand A, Bonhomme L, Collee M, Direct measurement of the capsular bag. $\mathrm{Am}$ Intraocular Implant Soc J 1984, 10: 475-6.

${ }^{21}$ Brems RN, Apple DJ, Pffefer BR et al. Posterior chamber intraocular lenses in a series of 75 autopsy eyes. 111: J. Cat Refract Surg 1987; 12: 367-71.

${ }^{22}$ Apple DJ, Lichtenstein SB, Herstein K, Letchinger SL, Park RB, Brems RN, Piest KL. Visual alterations caused by optic components of posterior intraocular lenses. $J$ Cat Refract Surg 1987;13: 431-5.

${ }^{23}$ Milaushas AT. Posterior capsule opacification after silicone lens implantation and its management. J Cat Refract Surgery 1987; 13: $644-$ 8.

${ }^{24}$ Lindstrom RL, Harris WS. Management of the posterior capsule following posterior chamber lens implantation. Am Intraocular Implant Soc J 1980;6: 255-8.

${ }^{25}$ Nishi O, Incidence of posterior capsule opacification in eyes with and without posterior chamber intraocular lenses. J Cat Refract Surg 1986; 12:519-22. 